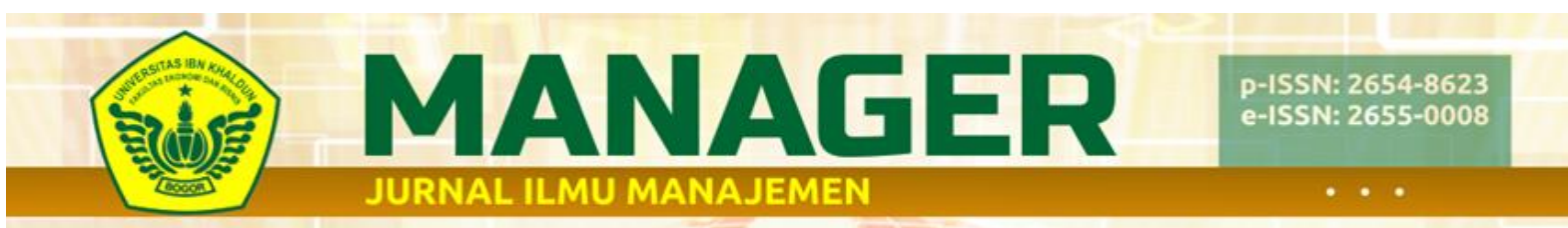

Vol. 3 No 1 Februari 2020 Hal 1-10 @c) (1) () http://ejournal.uikabogor.ac.id/index.php/Manager/index

\title{
PENGARUH KARAKTERISTIK INDIVIDU DAN LINGKUNGAN KERJA TERHADAP KINERJA KARYAWAN
}

\author{
Ajeng Puspita, M. Azis Firdaus, Rachmatullaily Tinakartika Rinda \\ Fakultas Ekonomi dan Bisnis Universitas Ibn Khaldun Bogor, Indonesia \\ Ajeng8396@gmail.com, azisfirdaus@gmail.com, lailyrinda@yahoo.com
}

\begin{abstract}
The purpose of this research was to determine how much influence the individual characteristics and work environment had on employee performance in the Department of Golf Operation Bogor Raya Golf Club. This study uses a survey method using primary data obtained from questionnaires and the samples used in this study were 35 respondents. The results of the correlation analysis between individual characteristics and work environment had on employee performance amounted to $R=0,627$ this shows a medium and positive relationship. The adjusted coefficient of Determination shows 0,355 which means that the magnitude of the influence of Individual Characteristics $\left(X_{1}\right)$ and Work Environment $\left(X_{2}\right)$ on employee performance $(Y)$ of $35,5 \%$ while the remaining $64,5 \%$ is influenced by other factors that are not included in this study. The regression equation is $Y=4,651+0,441 X_{1}+0,430 X_{2}$. Because $F$ count $=10,374>F$ table $=4,15$ then Ho is rejected $(H a$ accepted) means that there is a significant influence between individual characteristics $\left(X_{1}\right)$ and work environment $\left(X_{2}\right)$ had on employee performance $(Y)$.
\end{abstract}

Keywords : individual characteristics, work environment and employee performance.

\begin{abstract}
Abstrak
Penelitian ini bertujuan untuk mengetahui seberapa besar pengaruh Karaktersitik Individu dan Lingkungan Kerja terhadap Kinerja Karyawan Gepartemen Golf Operation Klub Golf Bogor Raya. Penelitian ini menggunakan metode survei dengan menggunakan data primer yang diperoleh dari kuesioner dan sampel penelitian ini sebanyak 35 orang. Hasil korelasi karakteristik individu dan lingkungan kerja terhadap kinerja karyawan menunjukan $R=0,627$ hal ini menunjukan bahwa hubungan antara variable Karakteristik Individu $\left(\mathrm{X}_{1}\right)$ dan Lingkungan Kerja $\left(\mathrm{X}_{2}\right)$ terhadap Kinerja Karyawan $(\mathrm{Y})$ adalah kuat dan positif. Koefisien Determinasi yang disesuaikan menunjukkan 0,355 memberikan arti bahwa besarnya pengaruh Karakteristik Individu $\left(\mathrm{X}_{1}\right)$ dan Lingkungan Kerja $\left(\mathrm{X}_{2}\right)$ terhadap Kinerja Karyawan (Y) sebesar 35,5\% sedangkan sisanya 64,5\% dipengaruhi oleh faktor-faktor lain yang tidak dimasukan dalam penelitian ini. Persamaan regresinya $Y=4,651+0,441 X_{1}+0,430 X_{2}$. Karena $F_{\text {hitung }}=10,347>F_{\text {tabel }}=4,15$ maka Ho ditolak (Ha diterima) berarti bahwa terdapat hubungan yang signifikan antara Karakteristik Individu $\left(\mathrm{X}_{1}\right)$ dan Lingkungan Kerja $\left(\mathrm{X}_{2}\right)$ terhadap Kinerja Karyawan (Y).
\end{abstract}

Kata Kunci : karakteristik individu, lingkungan kerja, kinerja karyawan 


\section{Pendahuluan}

\section{Latar Belakang}

Di dalam sebuah organisasi, manusia merupakan salah satu aspek sumber daya yang sangat penting, karena suatu organisasi tidak akan bisa berjalan apabila tidak ada manusia. Manusia merupakan penggerak setiap proses pekerjaan yang ada didalam perusahaan, betapapun canggihnya alat yang digunakan perusahaan tidak ada yang luput dari pengawasan manusia, maka dari itu sumber daya manusia hampir tidak dapat digantikan dengan sumber daya yang lainnya dan merupakan salah satu faktor yang menentukan berhasil atau tidaknya suatu organisasi atau perusahaan untuk mencapai tujuannya. Artinya manusia sangat dibutuhkan sekalipun jumlahnya sangat minimal.

Pentingnya peran manusia tidak lepas dari usaha perusahaan dalam mengelola SDM tersebut dimana pengelolaan yang baik akan menghasilkan SDM yang berkualitas dalam menjalankan pekerjaannya. Pengelolaan merupakan salah satu fungsi dari manajemen yang tidak bisa dihilangkan. Jika suatu perusahaan tidak bisa mengelola SDM dengan baik maka perusahaan tersebut tidak akan mengalami kemajuan, karena indikator kemajuan suatu perusahaan salah satunya dilihat dari kualitas SDM nya sebagai penopang perusahaan tersebut.

Keberadaan manusia merupakan sumber daya yang paling istimewa, keistimewaan yang ada pada manusia adalah satu-satunya sumber daya didalam perusahaan yang mempunyai pikiran, perasaan, dan kepribadian yang berbedaberbeda. Kepribadian pegawai yang berbeda-beda menjadikan pegawai mempunyai ciri khas tersendiri sehingga membentuk suatu karakteristik individu pada pegawai. Baik buruknya karakteristik individu pegawai tergantung bagaimana mereka mengaplikasikannya.

Karakteristik individu dalam suatu organisasi atau perusahaan juga sangat penting dalam menciptakan SDM yang berkualitas. Menurut Triatna (2016, hlm. 48) karakteristik individu meliputi minat, keahlian, pendidikan, dan pengalaman kerja. Minat adalah sikap yang membuat seseorang senang akan obyek kecenderungan atau ide-ide tertentu. Hal ini diikuti dengan perasaan senang dan kecenderungan untuk mencari obyek yang disenangi itu.

Selain karakteristik individu ada juga faktor yang berpengaruh langsung pada pegawai dan tidak dapat dipisahkan dalam tercapainya suatu tujuan perusahaan yaitu lingkungan kerja. Lingkungan kerja merupakan tempat dimana pegawai beraktivitas sehari-hari, dan segala sesuatu fisik atau non fisik yang ada di sekitar para pekerja yang mempengaruhi dirinya dalam menjalankan tugas yang menjadi tanggung jawabnya.

Lingkungan kerja juga akan mendukung tingkat kinerja para karyawan. Lingkungan kerja yang baik dan memuaskan karyawan tentu akan meminimalisir atau menekan kinerja karyawan yang kurang melayani konsumen atau masyarakat dengan baik. Begitu juga sebaliknya, keadaan lingkungan kerja yang nyaman, aman dan mendukung akan membuat karyawan baik yang berada di bagian produksi menjadi semakin ramah, bersemangat dan bergairah dalam melayani konsumen dan juga masyarakat sekitarnya. Hal ini dapat memberi pengaruh positif bagi kondisi psikologis karyawan. Lingkungan kerja dapat menciptakan hubungan kerja yang mengikat antara orang-orang yang ada 
didalam lingkungannya. Oleh karena itu, hendaknya diusahakan agar lingkungan kerja harus baik dan kondusif karena lingkungan kerja yang baik dan kondusif menjadikan karyawan merasa betah berada di ruangan dan merasa senang serta bersemangat untuk melaksanakan tugas- tugasnya sehingga kepuasan kerja akan terbentuk dan dari kepuasan kerja karyawan tersebut maka kinerja karyawan juga akan meningkat (Kamal, Soepeno, \& Firdaus, 2018). kinerja merupakan suatu fungsi dari motivasi dan kemampuan. Kinerja merupakan perilaku nyata yang di tampilkan setiap orang sebagai prestasi kerja yang disahilkan oleh karyawan sesuai dengan perannya dalam perusahaan. Kinerja karyawan merupakan suatu hal yang sangat penting dalam upaya perusahaan untuk mencapai tujuannya (Kamal dkk., 2018).

Berdasarkan fenomena diatas, tingkat karakteristik individu dan lingkungan kerja dalam suatu organisasi atau perusahaan dapat mempengaruhi kinerja karyawan. Tingkat keberhasilan perusahaan dalam mencapai tujuannya tidak lepas dari pengaruh kinerja karyawan itu sendiri.

\section{Rumusan Masalah}

Berdasarkan permasalahan yang ada, maka penulis dapat merumuskan masalah sebagai berikut: (1) Seberapa besar pengaruh karakteristik individu terhadap kinerja karyawan Departemen Golf Operation Klub Golf Bogor Raya? (2) Seberapa besar pengaruh lingkungan kerja terhadap kinerja karyawan Departemen Golf Operation Klub Golf Bogor Raya? (3) Seberapa besar karakteristik individu dan lingkungan kerja mempengaruhi kinerja karyawan
Departemen Golf Operation Klub Golf Bogor Raya?

\section{Metode Penelitian \\ Jenis Penelitian}

Dalam melakukan penelitian ini menggunakan metode kuantitatif dan desain konklusif dengan harapan dengan harapan untuk memperoleh hubungan atau pengaruh dari variable yang diteliti yaitu karakteristik individu seagai variable independen $\left(\mathrm{X}_{1}\right)$ dan lingkungan kerja $\left(\mathrm{X}_{2}\right)$, terhadap kinerja karyawan sebagai variable dependen (Y).

\section{Populasi dan Sampel}

Jumlah populasi karyawan Departemen Golf Operation Klub Golf Bogor Raya sebanyak 35 orang. Sehingga sampel yang digunakan sebanyak 35 orang dengan perhitungan teknik sampling jenuh.

\section{Sumber Data}

Sumber data yang digunakan dalam penelitian ini yaitu data primer dan data sekunder. Menurut Sujarweni (2014, hlm. 73-74) Data primer yaitu data yang diperoleh dari responden melalui kuisioner, kelompok fokus, dan panel, atau juga data hasil wawancara peneliti dengan narasumber. Sedangkan Data sekunder yaitu data yang didapat dari catatan, buku, majalah berupa laporan keuangan publikasi perusahaan, laporan pemerintah, artikel, buku-buku sebagai teori, majalah dan lain sebagainya.

\section{a. Teknik dan Cara Pengumpulan Data}

Cara pengumpulan data yang digunakan dalam penelitian ini yaitu wawancara, observsi, dan kuesioner. Kuesioner memiliki indicator dan menggunakan skala likert yang memiliki 5 (lima) angka penilaian dengan kriteria jawaban sebagai 
berikut : Sangat Setuju (SS) skor 5, Setuju (S) skor 4, Netral (N) skor 3, Tidak Setuju (TS) skor 2 dan Sangat Tidak Setuju (STS) skor 1.

\section{Metode Analisis}

a. Analisis Deskriptif

Menurut Sujarweni (2014, hlm. 113), statistik deskriptif berusaha menggambarkan berbagai karakteristik data yang berasal dari suatu sampel. Statistik deskriptif seperti mean, median, modus, persentil, desil, kuartil, dalam bentuk analisis angka maupun gambar atau diagram.

Tujuan analisis deskriptif dalam penelitian ini untuk mengetahui dan menggambarkan nilai rata-rata dari jawaban atau persepsi responden berdasarkan dari data yang telah dikumpulkan melalui data kuesioner terkait variable-variabel yang diteliti dalam penelitian ini, yaitu variable $\mathrm{X}_{1}$ (Karakteristik Individu), variable $\mathrm{X}_{2}$ (Lingkungan Kerja) dan variable $\mathrm{Y}$ (Kinerja).

b. Uji Validitas dan Relialibilitas

Uji validitas dilakukan untuk mengetahui apakah poin-poin dalam daftar pertanyaan mampu mendefiinisikan variabel yang akan diteliti. Menurut Riduan dan Sunarto (Riduan \& Sunarto, 2015, hlm. 80) pengujian validitas dengan menggunakan teknik korelasi "Pearson Product Moment" dengan tingkat kepercayaan $95 \%(\alpha=0,05)$ dilakukan dengan cara mengkorelasikan skor masing-masing item dengan skor totalnya. Sesuai dengan Sugiyono (Sugiyono, 2010, hlm. 357) yang menyatakan bahwa apabila $\mathrm{r}$ hitung $>\mathrm{r}$ tabel pada taraf signifikan $5 \%(a=0,05)$, dan $\mathrm{n}=35$ diperoleh $\mathrm{r}$ tabel $=0,324$, maka dapat dikatakan bahwa suatu instrumen adalah Valid dan ketika $r$ hitung < r tabel maka item adalah invalid.

Uji reabilitas merupakan ukuran suatu kestabilan dan konsistensi responden dalam menjawab hal yang berkaitan dengan kontruk-kontruk pertanyaan yang merupakan dimensi suatu variabel dan disusun dalam suatu bentuk kuisioner. Uji reabilitas menggunakan rumus Cronbach Alpha dapat dilakukan secara bersama-sama terhadap seluruh butir pertanyaan. Jika nilai Alpha > 0,60 maka dapat dikatakan reliable (V. W. Sujarweni, 2014, hlm. 172).

c. Uji Asumsi Klasik

Uji Normalitas

Uji normalitas adalah uji untuk mengukur apakah data yang kita memiliki distribusi normal sehingga dapat dipakai dalam statistik parametrik, jika data tidak berdistribusi normal dapat dipakai statistik non parametrik. Uji normalitas merupakan pengujian dengan cara membandingkan antara data yang kita miliki dengan data berdistribusi normal yang memiliki mean dan standar deviasi yang sama dengan data kita (W. Sujarweni, 2014, hlm. 102).

Uji Homogenitas

Uji homogenitas berfungsi untuk mengetahui sama tidaknya variansivariansi dua buah ditribusi atau lebih dan juga dilakukan untuk mengetahui apakah data dalam variabel $\mathrm{X}$ dan $\mathrm{Y}$ bersifat homogen atau tidak.

Uji Linearitas

Uji linieritas bertujuan untuk mengetahui apakah dua variabel mempunyai hubungan yang linier atau 
tidak secara signifikan. Menurut Sugiyono (2016, hlm. 265), salah satu asumsi dari analisis regresi adalah linearitas. Maksudnya apakah garis regresi antara $\mathrm{X}$ dan $\mathrm{Y}$ membentuk garis linier atau tidak.

\section{d. Analisis Inferensial}

Korelasi

Menurut (Riduan \& Sunarto, 2015, hlm. 80-81), salah satu analisis korelasi yaitu korelaso PPM (Pearson Product Moment). Tujuannya untuk mengetahui derajat hubungan dan kontribusi variable bebas (independent) cengan variable (dependent). Teknik analisis ini menggunakan data interval dan ratio dengan persyaratan tertentu.

\section{Koefisien Determinasi}

Menurut (Riduan \& Sunarto, 2015, hlm. 81) Koefisien determinasi digunakan untuk menyatakan besar kecilnya sumbangan variabel $X$ terhadap Y.

Regresi Linier Sederhana

Menurut (Riduan \& Sunarto, 2015, hlm. 96) Regresi sederhana dapat dianalisis karena didasari oleh hubungan fungsional atau hubungan sebab akibat (kausal) variabel bebas (X) terhadap variabel terikat $(\mathrm{Y})$.

Regresi Linier Berganda

Menurut (Riduan \& Sunarto, 2015, hlm. 108-110) analisi regresi ganda adalah pengembangan dari analisis regresi sederhana. Analisis ini digunakan untuk mengetahui seberapa besar pengaruh antara variabel bebas terhadap variabel terikat.

e. Uji Hipotesis

Uji hipotesis digunakan untuk menguji signifikan atau tidaknya hubungan variabel $\mathrm{X}$ dan $\mathrm{Y}$, terdapat 2 uji hipotesis yaitu :

Uji T (Parsial)

Setelah melakukan analisis korelasi maka perlu menghitung uji signifikansi. Menurut (Riduan \& Sunarto, 2015, hlm. 81), uji signifikansi berfungsi untuk mencari hubungan variabel $\mathrm{X}$ terhadap Y.

Uji F (Simultan)

Menurut Riduwan dan Sunarto (2015, hlm. 86) analisis korelasi ganda berfungsi untuk mencari besarnya hubungan dan kontribusi dua variabel bebas $(\mathrm{X})$ atau lebih secara simultan (bersama-sama) dengan variabel (Y). Uji simultan ini, bertujuan untuk menguji formula hipotesis $\mathrm{Ha}$ yang menjelaskan "terdapat pengaruh yang signifikan antara Karakteristik Individu dan Lingkungan Kerja Terhadap Kinerja Karyawan Departemen Golf Operation Klub Golf Bogor raya".

\section{Hasil Dan Pembahasan Uji Validitas dan Relialibilitas}

Penelitian ini menggunakan taraf signifikansi $95 \%(a=0,05)$, dan $\mathrm{n}=$ 35 diperoleh $r_{\text {tabel }}=0,324$, maka dapat dikatakan bahwa suatu instrument adalah valid. Dengan membandingkan nilai pada kolom Corrected Item-Total Correlation ( $\mathrm{r}_{\text {hitung }}$ ) dengan $\mathrm{r}_{\text {tabel }}$. Dari data hasil penelitian menunjukkan $>\left(\mathrm{r}_{\text {hitung }}\right)$ dapat dikatakan bahwa keseluruhan item penelitian adalah valid untuk digunakan sebagai instrument dalam penelitian. 
Dengan melihat data hasil penelitian meunjukkan Cronbach's Alpha >0,60 dapat disimpulkan bahwa pertanyaan dalam kuisioner variable Karakteristik Individu $\left(\mathrm{X}_{1}\right)$, Lingkungan Kerja $\left(\mathrm{X}_{2}\right)$, dan Kinerja (Y) adalah reliable dan dapat diterima.

a. Uji Asumsi Klasik

Uji Normalitas

Data yang digunakan dalam penelitian ini berdistribusi normal, karena dapat dilihat pada baris Asymp. Sig. (2-tailed) Karakteristik Individu > 0,05 yaitu sebesar 0,200. Asymp. Sig. (2-tailed) Lingkungan Kerja >0,05 yaitu sebesar 0,075. Asymp. Sig. (2tailed) Kinerja >0,05 yaitu sebesar 0,191 .

\section{Uji Homogenitas}

Nilai signifikansi variable Kinerja (Y) berdasarkan Karakteristik Individu $\left(\mathrm{X}_{1}\right)=0,336>0,05$, maka dapat disimpulkan bahwa data tersebut mempunyai variable yang sama atau homogen. Sedangkan nilai signifikansi variabek kinerja (Y) berdasarkan variable Lingkungan Kerja $\left(\mathrm{X}_{2}\right)=0,075>$ 0,05 , maka dapat disimpulkan bahwa data tersebut mempunyai variable yang sama atau homogen.

\section{Uji Linearitas}

Pada uji linearitas diperoleh nilai variabel Karakteristik Individu $\left(\mathrm{X}_{1}\right)$ dengan Kinerja $(\mathrm{Y})$ adalah $\mathrm{F}_{\text {hitung }}=$ $0,629<\mathrm{F}_{\text {tabel }}=4,15$ dan nilai variabel Lingkungan Kerja $\left(\mathrm{X}_{2}\right)$ dengan Kinerja $(\mathrm{Y})$ adalah $\mathrm{F}_{\text {hitung }}$ $=1,009<\mathrm{F}_{\text {tabel }}=4,15$, maka dapat disimpulkan bahwa terdapat hubungan linier secara signifikan diantara keduanya.

b. Analisis Pengaruh Antara Karakteristik Individu $\left(\mathrm{X}_{1}\right)$ dan Kinerja Karyawan (Y)

Analisis Korelasi

Dari hasil perhitungan menunjukkan nilai $\mathrm{R}=0,512$ terletak pada interval $0,40-0,59$ (Sedang), hal ini menunjukan bahwa hubungan antara variabel Karakteristik Individu $\left(\mathrm{X}_{1}\right)$ dan Kinerja Karyawan (Y) adalah Sedang dan positif. Berarti apabila $\mathrm{X}_{1}$ naik maka $\mathrm{Y}$ juga naik.

\section{Analisis Regresi}

Berdasarkan hasil perhitungan koefisien regresi dapat diketahui bahwa persamaan regresi yang terbentuk adalah $\mathrm{Y}=18,879+$ $0,550 \quad \mathrm{X}_{1}$. Interprestasi atau konstanta sebesar 18,879. Berarti apabila variabel bebas $\mathrm{X}_{1}$ (Karakteristik Individu) sama dengan nol, maka besarnya variable Y (Kinerja) adalah 18,879. Arah pengaruh dan koefisien regresi vatiabel $\mathrm{X}_{1}$ (Karaktersitik Individu) sebesar 0,550 ini berarti pengaruh Karakteristik Individu $\left(\mathrm{X}_{1}\right)$ terhadap Kinerja $(\mathrm{Y})$ adalah positif atau setiap kenaikan nilai skor variable $\mathrm{X}_{1}$ (Karakteristik Individu) sebesar 1, maka akan meningkatkan nilai skor variabel $\mathrm{Y}$ (Kinerja) sebesar 0,550.

\section{Analisis Koefisien Determinasi}

Hasil koefisien determinasi sebesar 0,240 atau $(24,0 \%)$ memberikan arti bahwa besarnya pengaruh 
Karakteristik Individu terhadap Kinerja Kayawan sebesar 24,0\% sedangkan sisanya $76 \%$ dipengaruhi oleh faktor-faktor lain yang tidak dimasukan dalam penelitian ini.

\section{Uji T (Parsial)}

$\mathrm{T}_{\text {hitung }}=3,425>\mathrm{T}_{\text {tabel }}=1,693$ maka Ho ditolak (Ha diterima) berarti bahwa terdapat hubungan yang signifikan antara Karakteristik Individu $\left(\mathrm{X}_{1}\right)$ dan terhadap Kinerja Karyawan (Y).

c. Analisis Pengaruh antara Variabel Lingkingan Kerja $\left(\mathrm{X}_{2}\right)$ dan Kinerja Karyawan (Y)

Analisis Korelasi

Dari hasil perhitungan tersebut menunjukkan $\mathrm{R}=0,487$ terletak pada interval 0,40 - 0,59 (Sedang), hal ini menunjukan bahwa hubungan antara variabel Lingkungan Kerja $\left(\mathrm{X}_{2}\right)$ dan Kinerja Karyawan (Y) adalah Sedang dan positif. Berarti apabila $\mathrm{X}_{2}$ naik maka Y juga naik.

\section{Analisis Regresi}

Berdasarkan hasil perhitungan koefisien regresi diketahui bahwa persamaan regresi yang terbentuk adalah $\mathrm{Y}=18,517+0,558 \quad \mathrm{X}_{2}$. interprestasi atau konstanta sebesar 18,517 berarti apabila variabel bebas $\mathrm{X}_{2}$ (Lingkungan Kerja) sama dengan nol, maka besarnya variabel Y (Kinerja) 18,517. Arah pengaruh dan koefisien regresi variabel $\mathrm{X}_{2}$ (Lingkungan Kerja) sebesar 0,558 ini berarti pengaruh Lingkungan Kerja $\left(\mathrm{X}_{2}\right)$ terhadap Kinerja (Y) adalah positif atau setiap kenaikan nilai skor variabel
$\mathrm{X}_{2}$ Lingkungan Kerja sebesar 1, maka akan meningkatkan nilai skor variabel Y (Kinerja) sebesar 0,558 .

Analisis Koefisien Determinasi Hasil koefisien determinasi sebesar 0,214 atau $(21,4 \%)$ memberikan arti bahwa pengaruh Lingkungan Kerja terhadap Kinerja Kayawan sangat kecil hanya sebesar $21,4 \%$ sedangkan sisanya $78,6 \%$ dipengaruhi oleh faktor-faktor lain yang tidak dimasukan dalam penelitian ini.

Uji Hipotesis Persial (Uji T)

$\mathrm{T}_{\text {hitung }}=3,203>\mathrm{T}_{\text {tabel }}=1,693$ maka Ho ditolak (Ha diterima) berarti bahwa terdapat hubungan yang signifikan antara Lingkungan Kerja $\left(\mathrm{X}_{1}\right)$ dan terhadap Kinerja Karyawan (Y).

d. Analisis Pengaruh Antara Karakteristik Individu $\left(\mathrm{X}_{1}\right)$ dan Lingkungan Kerja $\left(\mathrm{X}_{2}\right)$ terhadap Kinerja (Y)

Analisis Korelasi

Dari hasil perhitungan tersebut menunjukan $\mathrm{R}=0,627$ terletak pada interval 0,60 - 0,79 (Kuat), hal ini menunjukan bahwa hubungan antara variable Karakteristik Individu $\left(\mathrm{X}_{1}\right)$ dan Lingkungan Kerja $\left(\mathrm{X}_{2}\right)$ terhadap Kinerja Karyawan (Y) adalah kuat dan positif. Berarti apabila $\mathrm{X}_{1}$ dan $\mathrm{X}_{2}$ naik maka $\mathrm{Y}$ juga naik.

\section{Analisis Regresi}

Berdasarkan perhitungan koefisien regresi dapat diketahui bahwa persamaan regresi yang terbentuk adalah $\mathrm{Y}=4,651+0,441 \mathrm{X}_{1}+$ 
$0,430 \quad \mathrm{X}_{2} . \quad$ Interprestasi atau konstanta sebesar sebesar 4,651 berarti apabila variabel bebas $\mathrm{X}_{1}$ (Karakteristik Individu) dan $\mathrm{X}_{2}$ (Lingkungan Kerja) sama dengan nol, maka besarnya variabel $\mathrm{Y}$ (kinerja karyawan) adalah 4,651. Dengan kata lain, jika variabel bebas $\mathrm{X}_{1}$ (karakteristik Individu) dan $\mathrm{X}_{2}$ (Lingkungan Kerja) nilainya dianggap nol berarti besarnya variabel Y (Kinerja) adalah 4,651. Arah pengaruh dan koefisien regresi variabel $\mathrm{X}_{1}$ (Karakteristik Individu) sebesar 0,441 ini berarti pengaruh Karakteristik Individu $\left(\mathrm{X}_{1}\right)$ terhadap KInerja (Y) adalah positif atau setiap kenaikan nilai skor variabel Y Kinerja sebesar 1, maka akan meningkatkan nilai skor variabel Y (Kinerja) sebesar 0,441. Arah pengaruh dan koefisien regresi variabek $\mathrm{X}_{2}$ (Lingkungan Kerja) sebesar 0,430 ini berarti pengaruh Lingkungan Kerja $\left(\mathrm{X}_{2}\right)$ terhadap kinerja $(\mathrm{Y})$ adalah positif atau setiap kenaikan nilai skor variabel $\mathrm{X}_{2}$ Lingkungan Kerja sebesar 1, maka akan meningkatkan nilai skor variabel $\mathrm{Y}$ (Kinerja) sebesar 0,430.

\section{Analisis Koefisien Determinasi}

Hasil koefisien determinasi yang disesuaikan sebesar 0,355 atau (35,5\%), dengan begitu dapat diartikan bahwa besarnya pengaruh Karakteristik Individu $\left(\mathrm{X}_{1}\right)$ dan Lingkungan Kerja $\left(\mathrm{X}_{2}\right)$ terhadap Kinerja Karyawan (Y) sebesar $35,5 \%$ sedangkan sisanya $64,5 \%$ dipengaruhi oleh faktor-faktor lain yang tidak dimasukan dalam penelitian ini.

Uji Hipotesis Simultan (Uji F)

$\mathrm{F}_{\text {hitung }}=10,347>\mathrm{F}_{\text {tabel }}=4,15$ maka Ho ditolak (Ha diterima) berarti bahwa terdapat pengaruh yang signifikan antara Karakteristik Individu $\left(\mathrm{X}_{1}\right)$ dan Lingkungan Kerja $\left(\mathrm{X}_{2}\right)$ terhadap Kinerja Karyawan (Y).

\section{Kesimpulan dan Saran Kesimpulan}

1. Analisis hubungan antara variabel Karakteristik Individu $\left(\mathrm{X}_{1}\right)$ dan Kinerja Karyawan (Y)

Analisis Korelasi yang dilakukan menghasilkan $\mathrm{R}$ $=0,512$ terletak pada interval $0,40-0,59$ (Sedang), hal ini menunjukan bahwa hubungan antara variabel Karakteristik Individu $\left(\mathrm{X}_{1}\right)$ dan Kinerja Karyawan (Y) adalah kuat dan positif.

Hasil dari pengujian koefisien determinasi sebesar 0,240 atau $(24,0 \%)$ memberikan arti bahwa besarnya pengaruh Karakteristik Individu terhadap Kinerja Kayawan sebesar $24,0 \%$ sedangkan sisanya $76 \%$ dipengaruhi oleh faktor-faktor lain yang tidak dimasukan dalam penelitian ini.

Terdapat hubungan yang signifikan antara Karakteristik Individu $\left(\mathrm{X}_{1}\right)$ terhadap Kinerja Karyawan 
(Y) karena $\mathrm{T}_{\text {hitung }}=3,425>$

$\mathrm{T}$ tabel $=1,693$ maka Ho ditolak (Ha diterima).

2. Analisis hubungan antara variabel Lingkungan Kerja $\left(\mathrm{X}_{2}\right)$ dan Kinerja Karyawan (Y)

Analisis Korelasi yang dilakukan menghasilkan $\mathrm{R}$ $=0,487$ terletak pada interval $0,40-0,59$ (Sedang), hal ini menunjukan bahwa hubungan antara variabel Lingkungan Kerja $\left(\mathrm{X}_{2}\right)$ dan Kinerja Karyawan (Y) adalah Sedang dan positif.

Hasil dari pengujian koefisien determinasi sebesar 0,214 atau $(21,4 \%)$ memberikan arti bahwa pengaruh Lingkungan Kerja terhadap Kinerja Kayawan kecil hanya sebesar $21,4 \%$ sedangkan sisanya $78,6 \%$ dipengaruhi oleh faktorfaktor lain yang tidak dimasukan dalam penelitian ini.

Terdapat hubungan yang signifikan antara Lingkungan Kerja $\left(\mathrm{X}_{2}\right)$ dan Kinerja Karyawan (Y) karena $\mathrm{T}_{\text {hitung }}=3,203>\mathrm{T}$ tabel $=1,693$ maka Ho ditolak (Ha diterima).

3. Analisis hubungan antara variabel Karakteristik Individu $\left(\mathrm{X}_{1}\right) \quad$ dan Lingkungan Kerja $\left(\mathrm{X}_{2}\right)$ terhadap Kinerja Karyawan (Y)

Analisis korelasi yang dilakukan menghasilkan $\mathrm{R}$
$=0,627$ terletak pada interval 0,60 - 0,79 (Kuat), hal ini menunjukan bahwa hubungan antara variabel Karakteristik Individu $\left(\mathrm{X}_{1}\right)$ dan Lingkungan Kerja $\left(\mathrm{X}_{2}\right)$ terhadap Kinerja Karyawan (Y) adalah Kuat dan positif. Hasil dari pengujian koefisien determinasi yang disesuaikan sebesar 0,355 atau $(35,5 \%)$, dengan begitu dapat diartikan bahwa besarnya pengaruh Karakteristik Individu $\left(\mathrm{X}_{1}\right)$ dan Lingkungan Kerja $\left(\mathrm{X}_{2}\right)$ terhadap Kinerja Karyawan (Y) sebesar $\quad 35,5 \%$ sedangkan sisanya $64,5 \%$ dipengaruhi oleh faktorfaktor lain yang tidak dimasukan dalam penelitian ini.

Terdapat hubungan yang signifikan antara Karakteristik Individu $\left(\mathrm{X}_{1}\right)$ dan Lingkungan Kerja $\left(\mathrm{X}_{2}\right)$ terhadap Kinerja Karyawan $(\mathrm{Y})$. Karena $\mathrm{F}_{\text {hitung }}=10,347$ $>\mathrm{F}_{\text {tabel }}=4,15$ maka Ho ditolak (Ha diterima).

Saran

Berdasarkan hasil penelitian dan kesimpulan yang telah disajikan maka selanjutnya peneliti menyampaikan saran-saran yang kiranya dapat memberikan manfaat pada pihak-pihak yang terkait atas penelitian ini.

\section{Saran}

Dalam rangka meningkatkan kinerja 
karyawannya, Departemen Golf Operation Klub Golf Bogor Raya perlu memperhatikan dan menumbuhkan karakteristik individu yang baik sehingga akan dapat meningkatkan kinerja karyawannya dan juga akan sangat bermanfaat untuk menghadapi persaingan global yang kian memanas.

1) Penelitian ini juga diharapkan mampu memberikan kontribusi kepada perusahaan agar tetap mempertahankan lingkungan kerja yang baik dan kondusif. Agar dapat mendukung karyawannya untuk dapat bekerja dengan baik dan sesuai dengan yang diharapkan oleh perusahaan.

2) Bagi peneliti selanjutnya, hendaknya untuk mengembangkan penelitian ini dengan menggunakan variabel atau indikator yang berbeda sehingga dapat diperoleh informasi yang lebih lengkap tentang faktor-faktor yang mempengaruhi kinerja karyawan.

\section{Daftar Pustaka}

Busro, M. (2017). Manajemen Sumber Daya Manusia. Yogyakarta: expert.

Hasibuan, M. S. P. (2018). Manajemen Sumber Daya Manusia. Jakarta: PT Bumi Aksara.

Jacobis, G. V., \& Kojo, C. (2017). Pengaruh Karakteristik Individu Dan Lingkungan Kerja Terhadap Kinerja Pegawai Di Dinas Lingkungan Hidup Daerah Provinsi Sulawesi Utara. 8.
Kamal, A., Soepeno, \& Firdaus, A. (2018). Pemotivasian dan Lingkungan Kerja Terhadap Kinerja. 15.

Kasmir. (2016). Manajemen Sumber Daya Manusia (Teori dan Praktik). Jakarta: PT RajaGrafindo Persada.

Mangkunegara, A. P. (2015). Manajemen Sumber Daya Manusia Perusahaan. Bandung: PT. Remaja Rosdakarya.

Riduan, \& Sunarto. (2015). Pengantar Statistika Untuk Penelitian: Pendidikan, Sosial, Komunikasi, Ekonomi Dan Bisnis. Bandung: Alfabeta, Cv.

Riduwan, \& Sunarto. (2015). Pengantar Statistika Untuk Penelitian: Pendidikan, Sosial, Komunikasi, Ekonomi Dan Bisnis. Bandung: Alfabeta.

Robbins, S. P., \& Judge, T. (2014). Perilaku Organisasi. Jakarta: Salemba Empat.

Sedarmayanti. (2011). Tata Kerja dan Produktivitas Kerja. Bandung: CV. Mandar Maju.

S.P. Hasibuan, M. (2014). Manajemen : Dasar, Pengertian, dan Masalah. Jakarta: PT Bumi Aksara.

Sugiyono. (2010). Metode Penelitian Bisnis. Bandung: Alfabeta, Cv.

Sugiyono. (2016). Metode Penelitian Kuantitatif, Kualitatif, dan $R \& D$. Bandung: Alfabeta, cv.

Sujarweni, V. W. (2014). Metodologi Penelitian. Yogyakarta: Pustaka Baru Press.

Sujarweni, W. (2014). Metodologi

Penelitian. Yogyakarta:

Pustakabarupress.

Triatna, C. (2016). Perilaku Organisasi dalam Pendidikan. Bandung: PT. Remaja Rosdakarya. 